\title{
The Effects of In-Ovo Injected D-Glucose Monohydrate and Ascorbic Acid on Hatchability, Body Weight and Early Post-Hatch Performance of Geese
}

\author{
Yasin Baykalir, Seda Iflazoglu Mutlu, and Zeki Erisir
}

\section{ABSTRACT}

\begin{abstract}
The aim of the current study was to determine the impact of in-ovo injected DGlucose monohydrate and ascorbic acid on hatchability, body weight and early post-hatch performance of geese. The 360 eggs from a 50-wk-old Embden crossbred breeder flock were set in a single-stage incubator with 4 treatments. The experimental treatments were: (1) non-injected Control, (2) Dextrose $24 \mathrm{mg}$ / $0.5 \mathrm{~mL}$, (3) Vitamin C $10 \mathrm{mg}$ / $0.1 \mathrm{~mL}$ (4) Dextrose $24 \mathrm{mg}$ / $0.5 \mathrm{~mL}+$ Vitamin C $10 \mathrm{mg} / 0.1 \mathrm{~mL}$. At 11 and $18 \mathrm{~d}$ of incubation, the eggs were injected into the albumen manually under sterile conditions. At $25 \mathrm{~d}$ of incubation, the same amount of the agents was injected into the yolk sac of the fertile eggs with the same procedure. The hatchability of the Control and Dextrose + Vitamin C groups were statistically different $(P<0.05)$. Although there was a statistically insignificant difference, the highest value was recorded in the Dextrose + Vitamin $C$ group on the $25^{\text {th }}$-day. The hatchling weights were only influenced by the agents. The $25^{\text {th }}$-day Dextrose + Vitamin $\mathrm{C}$ treatment had the greatest values at body weights at hatch. There were no statistical differences by the injection days, agents and interactions regarding body weights at $7^{\text {th }}$-day post-hatch. In addition, there was no significant impact of different injection sites on both hatchling weight and, body weights of post-hatch $7^{\text {th }}$-day. It is suggested that the in-ovo injection should administrate on the $25^{\text {th }}$ day of incubation into the yolk sac in goose eggs with a mixture of D-Glucose monohydrate and ascorbic acid.
\end{abstract}

Keywords: ascorbic acid, carbohydrate, hatchability, goose, in-ovo injection

\author{
Published Online: March 31, 2021 \\ ISSN: $2736-6596$ \\ DOI : $10.24018 /$ ejvetmed.2021.1.1.7 \\ Yasin Baykalir* \\ Department of Animal Science, Faculty \\ of Veterinary Medicine, Firat University, \\ Elazig, Turkey \\ (e-mail: ybaykalir@firat.edu.tr) \\ Seda Iflazoglu Mutlu \\ Department of Animal Nutrition and \\ Nutritional Diseases, Faculty of \\ Veterinary Medicine, Firat University, \\ Elazig, Turkey \\ (e-mail: siflazoglu@firat.edu.tr) \\ Zeki Erisir \\ Department of Animal Science, Faculty \\ of Veterinary Medicine, Firat University, \\ Elazig, Turkey \\ (e-mail: zerisir@firat.edu.tr)
}

*Corresponding Author

\section{INTRODUCTION}

In-ovo technology first became available for vaccination delivery in broiler hatcheries approximately 26 years ago. The Marek's disease vaccine was commonly administered to broiler hatchlings with in-ovo machines. These machines capable of administering vaccine anywhere from 25,000 to 62,000 eggs per h (Peebles, 2018). Beyond the vaccination, giving the nutrients to poultry by in-ovo technique is getting popular due to regarding delay access the food after hatched (Roto et al., 2016). During the hatching period, the most important nutrient sources of the embryo are albumen and yolk. The nutrients in the yolk pass into the embryonic circulation from the yolk sac and towards the last days of the hatching, the nutrients remaining in the yolk sac are taken from the navel and meet the requirements of the chick until it reaches food and water (Bauer et al., 2013). During development, bird embryos use the limited energy, protein, lipid, vitamin, and mineral resources that were deposited in the egg due to the availability of the nutrients are limited (Uni et al., 2012). On the other hand, the hatching period has a substantial time, especially in the broiler when considering their life span (Retes et al., 2018). For this purpose, carbohydrates, proteins, nucleotides, vitamins, minerals, various antioxidant agents, prebiotics and probiotics, growth hormone, organic acids, plant extracts and some stimulants (caffeine, theophylline) were applied in-ovo (Peebles, 2018). Among several tested nutrients, carbohydrates are widely studied because their concentration inside the egg is $<1 \%$ of the total nutrients, and only $0.3 \%$ is free glucose (Campos et al., 2011). Although several studies have shown the benefits of carbohydrate inoculation in eggs (Salmanzadeh, 2012; Tako et al., 2004), the results are still inconsistent and depend on the type of carbohydrates inoculated (Kadam et al., 2013), site of injection in the egg, embryo developmental stage and genetics (Leitão et al., 2008; Santos et al., 2010).

Geese are seasonal egg producers that have low egg production. The eggs of geese are mainly used for reproduction and research purposes (Tserveni-Goussi and Fortomaris, 2011). Generally, they begin to lay at 40 to 50 weeks of age and produce only 30 to 45 eggs (weighing 120$170 \mathrm{~g}$ ) with low fertility and hatchability, depending on breed (Gumulka and Rozenboim, 2013). Therefore, it becomes more important to increase both egg production and gosling quality in commercial goose farming. Crossbreeding is widely utilized to increase egg production in geese. German origin Embden geese are the most popular breed for greater egg production. However, the low hatchability is still a 
problem amongst the geese flock in commercial production. To overcome this disadvantage, improving gosling quality in point of body weight may play an essential role. Indeed, some studies demonstrated that the carbohydrate inoculation into fertilized duck eggs improved body weight at hatch as well as in broiler chicken embryos (Tangara et al., 2010; Zhai et al., 2011).

Ascorbic acid does not exist in a freshly laid fertile egg and the synthesis of vitamin C; subsequently, it begins at 3 or 4 days as a result of endogenous biosynthesis by the developing embryo (Nowaczewski et al., 2012). In-ovo injection of ascorbic acid had a favourable impact on hatchability results, embryo weight at different incubation days (Zakaria et al., 1998). However, there has not been encountered a study conducted on in-ovo injection of some nutrients into fertilized goose eggs. Furthermore, it is emphasized that the incubation temperature, incubation period, breeding age, the type and amount of the agent used, and the injection site are also effective in the success of in-ovo application (Ohta and Kidd, 2001).

The objective of the current study was to determine the effect of in-ovo administration of D-Glucose monohydrate and ascorbic acid, and the mixture of them at different incubation days into goose fertile eggs on hatchability performance, hatching and $7^{\text {th }}$-day post-hatch weights, and liveability.

\section{MATERiALS AND Methods}

\section{A. In-ovo Injection Process and Incubation}

The study was conducted at a commercial goose farm in Elazig province of Turkey with approved by the NonInterventional Research Ethics Committee of Firat University in accordance with the guidelines for animal welfare and experimental protocol (protocol no: 2020/15-06). A total of 360 fertile goose eggs were used in this study. "The eggs were obtained from 50-week-old geese of a German-origin crossbred flock called "Mast goose". The D-Glucose monohydrate (Dextrose 5\% injection, USP) and ascorbic acid (Vitamin C $500 \mathrm{mg} / 5 \mathrm{~mL}$ ampoule injection, USP) were injected at the doses of $24 \mathrm{mg} / 0.5 \mathrm{~mL}(\mathrm{w} / \mathrm{v})$ and $10 \mathrm{mg} / 0.1$ $\mathrm{mL}(\mathrm{w} / \mathrm{v})$, respectively (Nowaczewski et al., 2012; Retes et al., 2018). At $11 \mathrm{~d}$ of incubation, 360 fertile eggs with viable embryos were identified by candling and weighed. The eggs were then randomly distributed into 4 groups of 90 eggs, each with a similar weight distribution (128.5 $\mathrm{g} \pm 1.64)$. The experimental treatments were: (1) non-injected Control, (2) Dextrose $24 \mathrm{mg} / 0.5 \mathrm{~mL}$, (3) Vitamin C $10 \mathrm{mg} / 0.1 \mathrm{~mL}$ (4) Dextrose $24 \mathrm{mg} / 0.5 \mathrm{~mL}+$ Vitamin C $10 \mathrm{mg} / 0.1 \mathrm{~mL}$. The solutions were supplied from a commercial drug facility. Injection was applied to 30 eggs in each group at $11^{\text {th }}, 18^{\text {th }}$, and $25^{\text {th }}$ days of incubation except for Control. The incubation period of goose eggs is around 28-30 days. We determined injection days by tracking the albumen position via candling. At $11^{\text {th }}$ day 50 per cent of the whole egg covered by albumen. The albumen covered approximately more than 80 per cent of the whole egg at $18^{\text {th }}$ day. The albumen totally disappeared at the $25^{\text {th }}$ day of the incubation period. At 11 and $18 \mathrm{~d}$ of incubation, eggs were removed from the incubator and, after candling to visualise the albumen, the injection site was sterilised with a solution of $70 \%$ ethyl alcohol prior to injection. Eggs were injected into the albumen manually with the mentioned doses using a sterile 21-gauge needle $(21 \mathrm{G} \mathrm{x}$
$1 \frac{1}{2}$ ). Immediately after the injection, the holes on the egg surface were sealed with paraffin. At $25 \mathrm{~d}$ of incubation, same amount of the agents was injected into yolk sac of the fertile eggs with same procedure above. All the injected eggs and the non-injected controls were transferred to hatching baskets and placed in a hatching cabinet. All injections were performed, with slight modifications, according to the previously published methods of Abdel-Moneim et al. (2020).

\section{B. Hatchability and Body Weight Measurements}

End of the hatching period, healthy and crippled chicks were counted. All remaining eggs were examined and classified as eggs with unhatched chicks and dead embryos. Hatchability was measured as the number of healthy chicks hatched as a percentage of injected eggs with living embryos. Middle embryonic death was considered when follicles and egg-tooth were prominent of broken examined unhatched eggs. Late embryonic death was accepted when feathering of the entire body of the chicks and whether yolk external or retracted. Hatchability, chick yield, embryonic mortalities and, liveability were examined followed formulas (Taha, 2011):

Hatchability (\%): (number of hatched chicks / number of total fertilised eggs) $\mathrm{x} 100$,

Chick yield (\%): (Average chick weight / average fresh incubated egg weight) $\mathrm{x} 100$,

Middle embryonic mortality (\%): (number of midembryonic mortalities / number of total fertilised eggs) x 100,

Late embryonic mortality (\%): (number of late embryonic mortalities / number of total fertilised eggs) x 100 ,

Liveability $(\%)$ : (number of live chicks at $7^{\text {th }}$-day posthatch / number of hatched chicks) x 100 .

Hatchling weights $(\mathrm{g})$ were measured individually on an electric balance at hatch $(\mathrm{n}=203$ goslings $)$ and at $7^{\text {th }}$-day ( $n=196$ goslings) post-hatch. The goslings were reared together on a deep litter system and tagged with different coloured foot rings to identify per different treatment.

\section{Statistical Analysis}

The sample size of the current study was determined by GPower 3.1 power analysis software (Faul et al., 2007). The effect of in-ovo injection sites on hatchling weights and at post-hatch $7^{\text {th }}$-day body weights was compared with One-way ANOVA test. Scheffe post hoc test was applied for revealing the differences between the groups. Two-way ANOVA with General Linear Model procedure was utilized in order to evaluate the injection days $\left(11^{\text {th }}, 18^{\text {th }}\right.$, and $25^{\text {th }}$ days $)$ and agents (Dextrose, Vit C, and Dextrose + Vit C) on body weights of hatching and weights of $7 \mathrm{~d}$ post-hatch. The hatchability of fertile eggs of the groups (Dextrose, Vit C, and Dextrose + Vit C) was compared with the Chi-Square test. Multiple comparisons between the groups were conducted the two by two contingency chi-square by Fisher's exact test. All tests were done by IBM ${ }^{2}$ SPSS 22 statistical package program. Statistical significance was considered when $\mathrm{P} \leq$ 0.05 (Fisher, 1935; Collins et al., 2009).

\section{RESULTS}

Hatchability of the Control, Dextrose, Vit $\mathrm{C}$ and Dextrose + Vit $\mathrm{C}$ treatments resulted in $76.70 \%, 53.37 \%, 56.67 \%$ and $45.57 \%$, respectively (Table 1$)$. The Dextrose $(53.37 \%)$ and 
Vit C (56.67\%) groups were similar regarding the hatchability rate $(\mathrm{P}>0.05)$. However, the Control $(76.70 \%)$ and Dextrose + Vit C (45.57\%) groups were statistically different $(\mathrm{P}<0.05)$. The $18^{\text {th }} \mathrm{d}$ of Dextrose treatment $(66.70 \%)$ and Dextrose + Vit $\mathrm{C}$ treatment $(36.70 \%)$ were different as well as in the $11^{\text {th }} \mathrm{d}$ Vit $\mathrm{C}$ treatment (53.40\%) and $11^{\text {th }} \mathrm{d}$ Dextrose + Vit C treatment $(20.00 \%)$ (Table 1$)$. Although there was no statistical difference, the highest value was recorded in the Dextrose + Vit $C$ group on the $25^{\text {th }}$-day $(80.00 \%)$. Middle embryonic mortality was higher in the Dextrose (15.56\%) and Dextrose + Vit C (15.56\%) groups than the Control (3.33\%) and Vit C (13.33\%) groups (Figure 1). Late embryonic mortality for the Dextrose + Vit $C$ group $(38.89 \%)$ was greater than in any of the in-ovo injected groups. Late embryonic mortality values for the Control, Dextrose, and Vit C were $20.00 \%, 31.11 \%$, and $30.00 \%$, respectively. Chick yield for the Dextrose + Vit $\mathrm{C}$ group $(71.29 \%)$ was superior to the Vit C $(69.53 \%)$, Control $(69.39 \%)$, and Dextrose $(67.29 \%)$ groups (Figure 1). Liveability of the groups was $95.65 \%, 95.66 \%$, and $98.55 \%$ in the Control, Vit C, and Dextrose + Vit C, respectively. There was no mortality occurred in the Dextrose group during $7 \mathrm{~d}$ post-hatch (Figure 2).

The body weights at hatch were determined as $88.96 \mathrm{~g}$, $87.70 \mathrm{~g}, 89.94 \mathrm{~g}$, and $92.94 \mathrm{~g}$ in the Control, Dextrose, Vit C, and Dextrose + Vit $C$ treatments, respectively (Table 2). Posthatch $7^{\text {th }}$-day body weights in the same order were $244.62 \mathrm{~g}$, $239.53 \mathrm{~g}, 243.94 \mathrm{~g}$, and $238.79 \mathrm{~g}$. It is seen that the hatchling weights was only influenced by the agents $(\mathrm{P}<0.05)$. Posthatch $7^{\text {th }}$-day body weights of the goslings were similar in all treatments $(\mathrm{P}>0.05)$. The $25^{\text {th }}$-day Dextrose + Vit $\mathrm{C}$ treatment had the greatest values at body weights at hatch $(97.1 \mathrm{~g})$. The $18^{\text {th }}$-day Dextrose treatment exhibited lower values at hatch $(86.53 \mathrm{~g})$ but the $25^{\text {th }}$-day Dextrose treatment exhibited higher body weights on the $7^{\text {th }}$-day post-hatch $(255.13 \mathrm{~g})$. There were no statistical differences by the injection days, agents and their interactions for body weights at $7^{\text {th }}$-day post-hatch $(\mathrm{P}>0.05)$. In addition, there was no significant impact of different injection sites on both hatchling weight and $7^{\text {th }}$-day post-hatch body weights $(\mathrm{P}>$ 0.05 ) (Table 3).

\section{DISCUSSION}

In-ovo application accepted as one of the alternative feeding methods in poultry. Many kinds of research were conducted mainly focused on delivering of various nutrients to the embryo by in-ovo technique. Carbohydrates and some sort of vitamins have been tested widely with this technique in some poultry species such as broilers, ducks, and turkeys (Zakaria et al., 1998; Nowaczewski et al., 2012).

Our investigation failed to demonstrate a significant impact of the in-ovo injection of vitamin $\mathrm{C}$ and dextrose on the hatchability of geese from fertilized eggs. Similar results were reported for broiler chickens and ducks (Nowaczewski et al., 2012). However, in this study, the nearest values to the Control were recorded at $25^{\text {th }}$ day mixture of the Dextrose + Vit C. Tangara et al. (2010) found that the hatchability of noninjected controls was $86 \%$, carbohydrate injected groups was $69 \%$ in ducks. According to a study, in broiler chickens, hatchability was $89.7 \%$ for the $3 \mathrm{mg}$ of vitamin $\mathrm{C}$ injection on the $17^{\text {th }}$ day of incubation but hatchability of non-injected controls was 95.9\% (Nowaczewski et al., 2012). Fatemi et al. (2020) also determined hatchability of vitamin D3 injected eggs as $91.84 \%$ whereas non-injected eggs' were $94.14 \%$. Based on these results, it can be concluded that the in-ovo application caused a decrease in hatching performance. Salmanzadeh (2012) implicated that an allergic reaction under the air sac that stopped the respiration of the developing embryo was responsible for reduced hatching performance of in-ovo carbohydrate administration. In commercial poultry production, optimum hatching performance cannot be achieved at all times. The situation is complicated by a number of factors affecting embryonic liveability. The stage of embryonic development at oviposition influences hatching performance. The pre-gastrula and early gastrula stages were prevalent in eggs from birds with poor hatching results, while eggs from birds with good hatching results had contained embryos at an advanced gastrula stage. Genetic improvement of the turkeys for the heavy mature body weight led to more frequently containing embryos at an early gastrula stage than from turkeys improved for low body weight. This study was also conducted under farm conditions that crossbreeding of Embden geese for achieving heavy mature body weight.

Thus, despite the beneficial effects of in-ovo glucose injection, the decrease in hatching performance may be associated with the embryonic developmental stage as a result of genetic improvement of the geese for heavy mature body weight in this study (Christiensen, 2001). On the other hand, the age of breeder goose may influence the developmental stage at oviposition. According to early reports, the development of embryos in eggs laid by older birds was more advanced than younger counterparts (Fasenko, 1992). The fact that the geese from which the eggs were collected 50 weeks old age in this study may explain this situation. This age can be accepted as the beginning of breeder matureness in the geese (Gumulka and Rozenboim, 2013). This study was started when towards the late summer. This season is when the egg production and fertility of geese begin to decline (Wang et al., 2002). In this case, a decrease in hatching performance can be expected for this study.

It is also emphasized that the nutrients utilization by the embryo to be effective depending on the in-ovo injection site (Ohta and Kidd, 2001). Albumen mixes with the amniotic fluid and is orally consumed by chick embryo after $14 \mathrm{~d}$ incubation period (Moran Jr, 2007). Although there is detailed information about the nutritional status of the chick embryo, there is no clear information about goose embryo, especially retrieval time of nutrient from albumen and yolk. In this study, the yolk sac injection had heavier body weight than albumen injection at hatch. The yolk sac is retracted towards the end of the hatching and accounts for approximately 15 to $20 \%$ of the hatchling weight, becoming 
European Journal of Veterinary Medicine www.ej-vetmed.org

TABLE I: CHI-SQUARE TABLE OF THE EFFECTS OF IN-OVO INJECTED OF DEXTROSE, ViT C, AND DEXTROSE + VIT C MIXTURE ON DIFFERENT DAYS OF INCUBATION ON THE HATCHABILITY

\begin{tabular}{|c|c|c|c|c|c|c|c|c|c|c|c|c|c|}
\hline \multicolumn{14}{|c|}{ Treatments } \\
\hline \multirow{2}{*}{\multicolumn{2}{|c|}{ Control }} & \multicolumn{3}{|c|}{ Dextrose $^{B}$} & \multicolumn{3}{|c|}{ Vit $C^{A B}$} & \multicolumn{3}{|c|}{ Dextrose + Vit $C^{A B}$} & \multicolumn{3}{|c|}{$\begin{array}{c}\text { Statistical analysis }= \\
(\text { significance })\end{array}$} \\
\hline & & $\begin{array}{l}11^{\text {th }} \\
\text { day }\end{array}$ & $\begin{array}{l}18^{\text {th }} \\
\text { day }\end{array}$ & $\begin{array}{l}25^{\text {th }} \\
\text { day }\end{array}$ & $\begin{array}{l}11^{\text {th }} \\
\text { day }\end{array}$ & $\begin{array}{l}18^{\text {th }} \\
\text { day }\end{array}$ & $\begin{array}{l}25^{\text {th }} \\
\text { day }\end{array}$ & $\begin{array}{l}11^{\text {th }} \\
\text { day }\end{array}$ & $\begin{array}{l}18^{\text {th }} \\
\text { day }\end{array}$ & $\begin{array}{l}25^{\text {th }} \\
\text { day }\end{array}$ & $X^{2}$ & $\mathrm{df}$ & $\mathrm{P}$ value \\
\hline Hatchability & 76.70 & 36.70 & $66.70^{x}$ & 56.70 & $53.30^{\mathrm{a}}$ & 46.70 & 70.00 & $20.00^{\mathrm{b}}$ & $36.70^{\mathrm{y}}$ & 80.00 & 52.42 & 9 & $<0.001$ \\
\hline
\end{tabular}

All data represent the mean value of 3 replicates per treatment.

Control is the non-injected treatment, Dextrose contained $24 \mathrm{mg}$ in $0.5 \mathrm{~mL}$, Vit C contained $10 \mathrm{mg}$ in $0.1 \mathrm{~mL}$, and Dextrose $+\mathrm{Vit} \mathrm{C}$ contained $24 \mathrm{mg}+10$ $\mathrm{mg}$ in $0.6 \mathrm{~mL}$ injection solution.

$\mathrm{X}^{2}=$ Chi-square table value, $\mathrm{df}=$ degree of freedom.

Means within a row not sharing a common superscript are significantly different at $\mathrm{P} \leq 0.05$.

TABLE II: THE EFFECTS OF IN-OVO INJECTED OF DEXTROSE, VIT C, AND DEXTROSE + ViT C MIXTURE ON DIFFERENT DAYS OF INCUBATION ON THE BODY WEIGHT OF GOSLINGS AT HATCH, AND 7 D POST-HATCH.

\begin{tabular}{|c|c|c|c|c|c|c|c|c|c|c|c|c|c|c|}
\hline \multicolumn{15}{|c|}{ Treatments } \\
\hline \multicolumn{2}{|c|}{$\begin{array}{l}\text { Control } \\
(\mathrm{n}=69)\end{array}$} & \multicolumn{3}{|c|}{$\operatorname{Dextrose}^{B}(n=48)$} & \multicolumn{3}{|c|}{ Vit $C^{A B}(n=51)$} & \multicolumn{3}{|c|}{ Dextrose + Vit $C^{A B}(n=35)$} & \multicolumn{4}{|c|}{ Statistical analysis $=($ significance $)$} \\
\hline & & $\begin{array}{l}11^{\text {th }} \\
\text { day }\end{array}$ & $\begin{array}{l}18^{\text {th }} \\
\text { day }\end{array}$ & $\begin{array}{l}25^{\text {th }} \\
\text { day }\end{array}$ & $\begin{array}{l}11^{\text {th }} \\
\text { day }\end{array}$ & $\begin{array}{l}18^{\text {th }} \\
\text { day }\end{array}$ & $\begin{array}{l}25^{\text {th }} \\
\text { day }\end{array}$ & $\begin{array}{l}11^{\text {th }} \\
\text { day }\end{array}$ & $\begin{array}{l}18^{\text {th }} \\
\text { day }\end{array}$ & $\begin{array}{l}25^{\text {th }} \\
\text { day }\end{array}$ & SEM & $\mathrm{D}$ & $\mathrm{T}$ & $\mathrm{D} \times \mathrm{T}$ \\
\hline $\begin{array}{l}\text { Hatchling } \\
\text { weights } \\
\text { (g) }\end{array}$ & 88.96 & 87.78 & 86.53 & 88.78 & 86.68 & 91.69 & 91.45 & 94.19 & 87.53 & 97.10 & 3.13 & NS & $*$ & NS \\
\hline $\begin{array}{c}7^{\text {th }} \text {-day } \\
\text { body } \\
\text { weights } \\
\text { (g) }\end{array}$ & 248.77 & 238.33 & 225.14 & 255.13 & 242.69 & 244.62 & 244.50 & 229.80 & 236.85 & 249.73 & 12.39 & NS & NS & NS \\
\hline
\end{tabular}

All data represent the mean value of 3 replicates per treatment.

Control is the non-injected treatment, Dextrose contained $24 \mathrm{mg}$ in $0.5 \mathrm{~mL}$, Vit C contained $10 \mathrm{mg}$ in $0.1 \mathrm{~mL}$, and Dextrose $+\mathrm{Vit} \mathrm{C}$ contained $24 \mathrm{mg}+10$ $\mathrm{mg}$ in $0.6 \mathrm{~mL}$ injection solution

$\mathrm{SEM}=$ Standard Error Mean, $\mathrm{D}=$ Days, $\mathrm{T}=$ Treatments, $\mathrm{D} \times \mathrm{T}=$ Days $\mathrm{x}$ Treatments interaction

Means within a row not sharing a common superscript are significantly different at $\mathrm{P} \leq 0.05$.
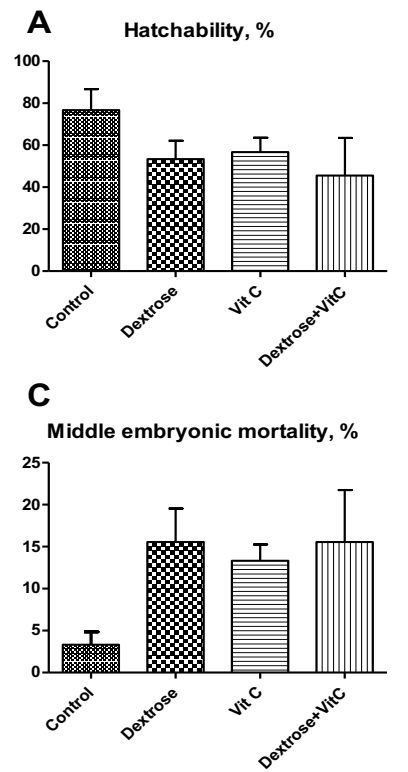

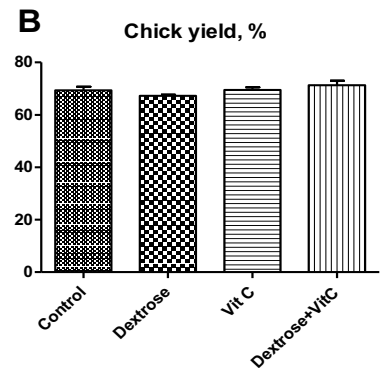

D

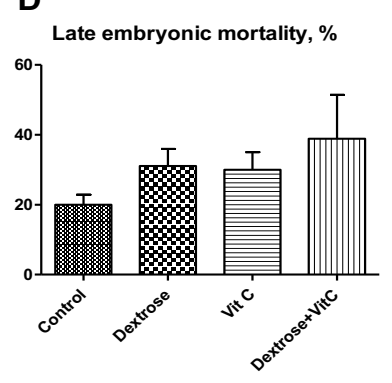

Fig. 1. Hatchability, chick yield and embryonic mortalities of the treatment groups 
TABLE III: THE EFFECT OF IN-OVO INJECTION SITE ON THE HATCHLING WEIGHT AND 7 D POST-HATCH BODY WEIGHTS OF GOSLINGS

\begin{tabular}{lcc}
\hline Site of injection & Hatchling weight $(\mathrm{g})$ & $7^{\text {th }}$-day body weight $(\mathrm{g})$ \\
\hline Control & $89.51 \pm 2.83$ & $248.77 \pm 12.13$ \\
Albumen & $88.54 \pm 1.25$ & $240.25 \pm 5.09$ \\
Yolk sac & $92.66 \pm 1.63$ & $239.14 \pm 5.86$ \\
\hline \multicolumn{1}{c}{ P-value } & 0.128 & 0.690 \\
\hline
\end{tabular}

All data represent the mean and standard error mean value of 3 replicates per treatment.

Control is the non-injected treatment.

crucial for survival after hatch as the only source of nutrients until exogenous feeding is provided to the chicks (Givisiez et al., 2020). It contains macromolecular complexes comprising lipids, proteins, vitamins, minerals, and other essential micronutrients (Bauer et al., 2013). Therefore, nutrients that are administered into yolk sac may more promote hatchling weight than those administered into albumen. This case may be also related to in-ovo injection time has not been specified accurately during incubation that albumen orally consumed by the goose embryo at $11^{\text {th }}$ and $18^{\text {th }}$ days. By the way, the time of albumen consuming orally by goose embryo has not been clearly known. In a study, injection of carbohydrates into the amnion of the duck fertile eggs enhanced liver glycogen levels so body weights. The high correlation determined in the mentioned study between liver glycogen concentration and body weight (Tangara et al., 2010).

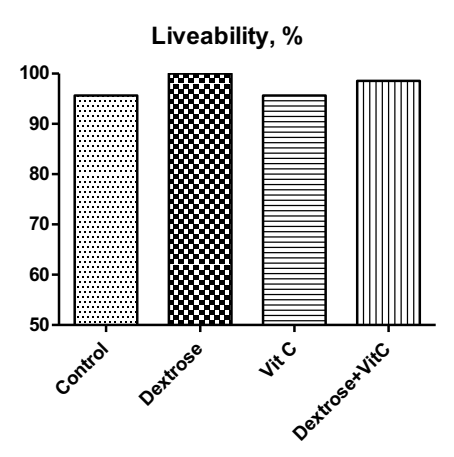

Fig. 2. Liveability of the treatment groups

\section{CONCLUSION}

According to the results of the current study, it is suggested that the in-ovo injection should applicate on $25^{\text {th }}$ day of incubation into yolk sac in goose eggs with a mixture of DGlucose monohydrate and ascorbic acid. In-ovo applications have not sufficiently studied on goose eggs regarding nutrient types, injection time and, sites. The essential two points should be evaluated well in terms of profitability in commercial poultry production considering in-ovo administration; reduced hatchability and increased hatchling weight. It may be more beneficial to reveal the potential contribution of in-ovo applications in goose species with low fertility and egg number. For the comprehension of the effects of nutrients administered into goose eggs on the growth performance, the birds should be farmed until slaughter age.

\section{REFERENCES}

[1] Abd El-Moneim, A.M.E., El-Wardany, I., Abu-Taleb, A.M., Wakwak, M.M., Ebeid, T.A., \& Saleh, A. A. (2020). Assessment of in ovo administration of bifidobacterium bifidum and bifidobacterium longum on performance, ileal histomorphometry, blood hematological, and biochemical parameters of broilers. Probiotics and Antimicrobial Proteins, 12, 439-450.

[2] Bauer, R., Plieschnig, J.A., Finkes, T., Riegler, B., Hermann, M., \& Schneider, W.J. (2013). The developing chicken yolk sac acquires nutrient transport competence by an orchestrated differentiation process of its endodermal epithelial cells. Journal of Biological Chemistry, 288, 1088-1098.

[3] Campos, A.M.A., Rostagno, H.S., Gomes, P.C., Silva, E.A., Albino, L.F.T., \& Nogueira, E.T. (2011). Efeito da inoculação de soluções nutritivas in ovo sobre a eclodibilidade e o desempenho de frangos de corte. Revista Brasileira de Zootecnia, 40, 1712-1717.

[4] Christensen, V.L. (2001). Factors associated with early embryonic mortality. World's Poultry Science Journal, 57, 359-372.

[5] Collins, L.M., Dziak, J.J., \& Li, R. (2009). Design of experiments with multiple independent variables: a resource management perspective on complete and reduced factorial designs. Psychological Methods, 14, 202-224.

[6] Fasenko, G.M. (1992). Factors influencing fertility, preincubation embryo development, and embryo viability in domestic fowl. MS Diss. University of Alberta, Edmonton.

[7] Fatemi, S.A., Elliott, K.E.C., Bello, A., Durojaye, O.A., Zhang, H.J. \& Peebles, E.D. (2020). The effects of in ovo injected vitamin D3 sources on the eggshell temperature and early posthatch performance of Ross 708 broilers. Poultry Science, 99, 1357-1362.

[8] Faul, F., Erdfelder, E., Lang, A.G., \& Buchner, A. (2007). G*Power 3: A flexible statistical power analysis program for the soc ial, behavioral, and biomedical sciences. Behavior Research Methods, 39, 175-191.

[9] Fisher, R.A. (1935). The Design of Experiments. Oliver and Boyd. Edinburgh.

[10] Givisiez, P.E.N., Moreira Filho, A.L.B., Santos, M.R.B., Oliveira, H.B., Ferket, P.R., Oliveira, C.J.B., \& Malheiros, R.D. (2020). Chicken embryo development: Metabolic and morphological basis for in ovo feeding technology. Poultry Science, 99, 6774-6782.

[11] Gumułka, M., \& Rozenboim, I. (2013). Mating activity of domestic geese ganders (Anser anser f. domesticus) during breeding period in relation to age, testosterone and thyroid hormones. Animal Reproduction Science, 142, 183-190.

[12] IBM SPSS 22. Licensed materials property of IBM CorporationC copyright IBM corporation and other(s). International.

[13] Kadam, M.M., Barekatain, M.R., Bhanja, S.K., \& Iji, P.A. (2013). Prospects of in ovo feeding and nutrient supplementation for poultry: The science and commercial applications-A review. Journal of the Science of Food and Agriculture, 93, 3654-3661.

[14] Leitão, R.A., Leandro, N.S.M., Café, M.B., Stringhini, J.H., Pedroso, A.A. \& Chaves, L.S. (2008). Inoculation of glucose in ovo of broiler breeders/eggs: incubation parameters and initial performance. Ciência Animal Brasileira, 9, 847-855.

[15] Moran Jr, E.T. (2007). Nutrition of the developing embryo and hatchling. Poultry Science, 86, 1043-1049.

[16] Nowaczewski, S., Kontecka, H., \& Krystianiak, S. (2012). Effect of in ovo injection of vitamin $\mathrm{C}$ during incubation on hatchability of chickens and ducks. Folia Biologica, 60, 93-97.

[17] Ohta, Y. \& Kidd, M.T. (2001). Optimum site for in ovo amino acid injection in broiler breeder eggs. Poultry Science, 80, 1425-1429.

[18] Peebles, E.D. (2018). In ovo applications in poultry: A review. Poultry Science, 97, 2322-2338.

[19] Retes, P.L., Clemente, A.H.S., Neves, D.G., Esposito, M., Makiyama, L., Alvarenga, R.R., Pereire, L.J. \& Zangeronimo, M.G. (2018). In ovo feeding of carbohydrates for broilers - A systematic review. Journal of Animal Physiology and Animal Nutrition, 102, 361-369.

[20] Roto, S.M., Kwon, Y.M. \& Ricke, S.C. (2016). Applications of in ovo technique for the optimal development of the gastrointestinal tract and the potential influence on the establishment of its microbiome in poultry. Frontiers in Veterinary Science, 3, 63-75.

[21] Salmanzadeh, M. (2012). The effects of in-ovo injection of glucose on hatchability, hatching weight and subsequent performance of newlyhatched chicks. Brazilian Journal of Poultry Science, 14, 137-140.

[22] Santos, T.T., Corzo, A., Kidd, M.T., McDaniel, C.D., Torres Filho, R.A. \& Araújo, L.F. (2010). Influence of in ovo inoculation with various nutrients and egg size on broiler performance. Journal of Applied Poultry Research, 19, 1-12.

[23] Taha, A.E. (2011). Analyzing of quail eggs hatchability, quality, embryonic mortality and malpositions in relation to their shell colors. Online Journal of Animal and Feed Research, 1, 267-273. 
[24] Tako, E., Ferket, P.R., \& Uni, Z. (2004). Effects of in ovo feeding of carbohydrates and $\beta$-Hydroxy- $\beta$-Methylbutyrate on the development of chicken intestine. Poultry Science, 83, 2023-2028.

[25] Tangara, M., Chen, W., Xu, J., Huang, F.R. \& Peng, J. (2010). Effects of in ovo feeding of carbohydrates and arginine on hatchability, body weight, energy metabolism and perinatal growth in duck embryos and neonates. British Poultry Science, 51, 602-608.

[26] Tserveni-Goussi, A., \& Fortomaris, P. (2011). Production and quality of quail, pheasant, goose and turkey eggs for uses other than human consumption. In: Improving the Safety and Quality of Eggs and Egg Products (Nys Y, Bain M and Van Immerseel F eds.). pp. 509-537. Woodhead Publishing. Cambridge.

[27] Uni, Z., Yadgary, L., \& Yair, R. (2012). Nutritional limitations during poultry embryonic development. Journal of Applied Poultry Research, $21,175-184$.

[28] Wang, S.D., Wang, C.M., Fan, Y.K., Jan, D.F., \& Chen, L.R. (2002). Effect of extreme light regime on production and characteristics of egg in laying geese. Asian-Australasian Journal of Animal Sciences, 15, 1182-1185.

[29] Zakaria, A.H., Al-Latif, A.A., \& Al-Anezi, M.A. (1998). Effect of ascorbic acid on embryonic development, hatch time and growth of extended delayed placement of broiler chickens. Archiv fur Geflugelkunde, 62, 11-15.

[30] Zhai, W., Rowe, D.E., \& Peebles, E.D. (2011). Effects of commercial in ovo injection of carbohydrates on broiler embryogenesis. Poultry Science, 90, 1295-1301. 